\title{
SINGULARIZAÇÃO DE IDENTIDADES E CONSTRUÇÃO DE SUBJETIVIDADES NA PERSPECTIVA DA CULTURA VISUAL
}

\author{
Mariana Binato de Souza* \\ Viviane Diehl** $^{*}$
}

\section{Resumo}

Esta pesquisa tem como temática a singularização da identidade e a construção da subjetividade por meio de proposições de ensino em artes visuais realizadas no contexto da Creche Estação dos Ventos, na cidade de Santa Maria, com pré-adolescentes de idades entre 10 e 13 anos. A cultura visual foi abarcada neste contexto como elemento facilitador da aproximação dos colaboradores com a temática, pois esta busca relacionar a cultura e as visualidades presentes no cotidiano a partir de um olhar crítico, tanto individual quanto em grupo. Isto colaborou no processo abordado, no qual se utilizaram fragmentos da metodologia dos projetos de trabalho pela sua abordagem facilitadora, que fez parte do processo de aproximação dos colaboradores e, consequentemente, da possibilidade de singularização das identidades e construção de subjetividades.

Palavras chave: identidade, subjetividade, cultura visual, ensino de artes visuais.

\begin{abstract}
This research's theme is the singularity of identity and subjectivity construction by proposing in the visual arts which was performed in the context of the "Estação dos Ventos" (Wind Station) child care center in Santa Maria city with preteens aged between 10 and 13 years old. Visual culture has been comprised here as a facilitator on bringing the contributors with the theme, as it seeks to relate culture and visualities present in everyday life from a critical look at both individual and group. Collaborating in the process by addressing both identities and subjectivities, this research has made use of fragments of the methodology of work projects for its facilitative approach that belonged of the process of approaching the contributors, and therefore their possibility on identity singularizing and subjectivities construction.
\end{abstract}

Keywords: identity, subjectivity, visual culture, visual arts education.

\footnotetext{
* Licenciada em Artes Visuais (2011).

** Orientadora da pesquisa. Doutoranda em Educação na UFSM. Professorartista e membro do Grupo de Estudos e Pesquisas em Arte, Educação e Cultura (GEPAEC), diretório CNPq. Artista Plástica do Atelier Vivie Diehl.
} 


\section{Permeando as relações e construções desta pesquisa}

A temática desta pesquisa se dá em torno da singularização da identidade ${ }^{1}$ e da construção da subjetividade ${ }^{2}$ através de proposições em artes visuais pela perspectiva da cultura visual. Questionamos quais subjetividades pré-adolescentes se produzem no contexto educativo de um processo pedagógico em artes visuais, que se propõe a singularizar identidades a partir do reconhecimento dos colaboradores da pesquisa como sujeitos de si. Dessa forma, problematizando esse questionamento, propiciando a reflexão e interação dos membros da pesquisa, tanto individualmente quanto através da relação que se dá entre os colaboradores, como forma de promover a subjetividade de cada um.

Para que ocorra essa relação entre os alunos, o propositor, a identidade e a subjetividade, foram estabelecidas questões de pesquisa que nortearão tal estudo, como os conceitos de identidade e subjetividade trazidos por Hall (2000), Gallo (1998); os conceitos advindos da perspectiva da cultura visual, abarcados por Martins (2007) e Hernández $(2000,2007,2011)$, entre outros autores, que serão tratados no texto a fim de sustentar esta pesquisa.

Esses aspectos são utilizados como norteadores da pesquisa por favorecerem o processo, desde a elaboração do referencial teórico, a construção e atuação nas oficinas, até o momento de compreensão dos achados da pesquisa e de interpretação, a partir do que foi estudado e percebido durante todo o percurso.

A Creche Estação dos Ventos, instituição que abriga crianças de 0 a 13 anos, está localizada no assentamento do $\mathrm{Km} \mathrm{3}$, bairro da cidade de Santa Maria, RS, e foi o local de estudo. A proposição desta pesquisa trouxe aspectos como a busca e a singularização da identidade e da subjetividade dos abrigados, visto que, em muitos momentos, crianças e adolescentes perdem seus referenciais de identidade, principalmente pelo motivo de viverem à margem da sociedade. Portanto, são percepções sociais em relação aos aspectos financeiros e empregatícios, considerando-se que a maioria desses préadolescentes são filhos de catadores de materiais recicláveis, profissão considerada à margem da sociedade, numa região que fica localizada muito afastada do centro da cidade e, por ser espaço de invasão, receber um olhar carregado de conceitos préestabelecidos pela população adjacente.

Conhecendo a história da Creche Estação dos Ventos, o local onde fica situada, e constatando certa falta de condições adequadas - tanto financeiras quanto de

\footnotetext{
1 Entendo singularização de identidades como uma forma de abordar e perceber como cada indivíduo se compreende como sujeito; singularizar este sujeito é uma possibilidade de construir problematizações que o façam entender como ele se constitui e se relaciona com o mundo no qual está inserido.

${ }^{2}$ A construção da subjetividade se dá a partir da troca com os indivíduos os quais nos relacionamos, sendo assim, é algo que se constrói e não depende somente da identidade de cada um, soma-se a outras identidades a fim de que esta troca se estabeleça e se construam subjetividades.
} 
infraestrutura, especialmente no que se refere ao público voluntário qualificado para atendê-la, no desenvolvimento de atividades para o público infantil e pré-adolescente decidi atuar dentro do contexto da creche, de forma a propiciar diferentes diálogos e percepções com os pré-adolescentes, tendo como objetivo a singularização de identidades e a produção da subjetividade de cada um.

Assim, este estudo trouxe, para o contexto dos colaboradores da pesquisa, propostas que permeiam as artes visuais e que possam servir de pontes entre suas vidas cotidianas e individuais. Isto como forma de trabalhar a identidade pela valorização do eu, dos meus lugares, das minhas percepções, das minhas reflexões, fazendo com que o meio seja, além de dispositivo, parte do processo de singularização da identidade.

A proposta de trabalho através de oficinas, aqui vista como um fator colaborador no resgate da subjetividade e da singularização da identidade dos pré-adolescentes, foi realizada através de dois encontros semanais, visando desenvolver atividades que pudessem colaborar com o objetivo desta pesquisa, tendo como caminho a educação do sujeito por meio das artes visuais, foco deste estudo. O objetivo do trabalho foi confrontar as subjetividades dos colaboradores da pesquisa e promover oficinas pedagógicas em artes visuais, que dessem conta de problematizar a singularização da identidade dos pré-adolescentes, tendo como referência o meio onde vivem.

Nesta pesquisa, o planejamento dos encontros teve base na metodologia dos projetos de trabalho como facilitadores do processo de docência. Estes puderam contribuir no processo de aproximação com os colaboradores, estabelecendo-se um enfrentamento das subjetividades dos pré-adolescentes em foco na pesquisa, a fim de eleger as abordagens e temáticas que pudessem ser facilitadoras no processo.

Como forma de instigá-los a refletirem sobre o assunto e envolverem-se na pesquisa, escolhi como mote o contexto social onde estão inseridos. Através da educação das artes visuais e da perspectiva da cultura visual, podem-se promover mecanismos facilitadores no ensino de artes visuais, bem como a aproximação entre o universo no qual os colaboradores estão inseridos e o universo da pesquisadora.

Utilizei ainda, como material de produção de dados, os diários reflexivos, algumas fotografias e as produções desenvolvidas pelos colaboradores, material que foi facilitador no momento da interpretação dos achados da pesquisa.

Este estudo, primeiramente, trata do embasamento teórico que utilizei para fundamentar o tema, subdividido em panoramas referentes à identidade e à subjetividade, cultura visual e o contexto educativo das artes visuais. Em seguida, abordo a metodologia usada no projeto e, na sequencia, como se deu a compreensão dos achados da pesquisa, subdividida em aspectos referentes à identidade e à subjetividade evidenciadas pelos colaboradores, à perspectiva da cultura visual percebida nos encontros, e a minha 
reflexão frente à educação das artes visuais baseada em aspectos da metodologia de projetos de trabalho.

\section{Para conceituar e definir este processo}

$\mathrm{Na}$ contemporaneidade, a educação das artes visuais tem se demonstrado facilitadora, principalmente quando se fala de uma educação para a significação individual e coletiva, visto que pode tomar direcionamentos que proporcionem um olhar diferenciado para si, e também momentos de troca entre os indivíduos, favorecendo a produção da subjetividade de cada um por meio da relação com o outro. Essa troca se dá, muitas vezes, através de elementos advindos da perspectiva da cultura visual, a qual propicia aos colaboradores a reflexão do olhar frente às imagens que estão no entorno, no cotidiano.

\section{Relações subjetivas e construções identitárias, o enlace entre o que se constrói e como se relaciona}

Promover a singularização da identidade e tratar sobre a subjetividade são questões desafiadoras, pois, além de serem temáticas que abrangem pessoalidades dos colaboradores envolvidos na pesquisa, necessitam de envolvimento e de abertura de cada um frente às propostas que possam promover estes conceitos, remetendo à vida de cada um dos envolvidos. Para essa aproximação, como já citado, utilizei a perspectiva da cultura visual e algumas contribuições da metodologia por projetos de trabalho. Busquei autores a fim de promover um diálogo com os conceitos de subjetividade e identidade, construindo enlaces entre esses dois temas.

Hernández (2007, p. 72) conceitua de uma forma muito precisa e direta o que entende por identidade:

\footnotetext{
Identidade tem a ver com a caracterização dos indivíduos mediada pela linguagem e determinadas práticas sociais. Portanto, é dada culturalmente e se apresenta como naturalizada e estável, oferecendo elementos de discriminação em relação a grupos com afinidades de gênero, etnia, religião ou pátria.
}

Para poder pensar a identidade através dessa conceituação que traz as práticas sociais, compreendo que devemos saber, de antemão, onde nossos colaboradores estão inseridos e qual contexto social os cerca, bem como as pessoas com as quais esses indivíduos se relacionam. Entendo a identidade para além de um elemento construído a partir das relações pessoais internas com o mundo, algo fundamental para que cada um possa 
entender qual seu papel diante de uma sociedade construída. A identidade de cada um muitas vezes pode se tornar o reflexo do meio onde o indivíduo vive e atua socialmente. Assim, compreendo que a cultura está diretamente atrelada à busca de sentido e significado da identidade pessoal. Silva (2000, p.69) traz, em seu vocabulário crítico sobre a teoria cultural e educacional, um conceito sobre a identidade cultural,

\begin{abstract}
no contexto das discussões sobre multiculturalismo e sobre a chamada 'política de identidade', o conjunto de características que distinguem os diferentes grupos sociais e culturais entre si. De acordo com a teorização pós-estruturalista, que fundamenta boa parte dos Estudos Culturais contemporâneos, a identidade cultural só pode ser compreendida em sua conexão com a produção da diferença, concebida como um processo social discursivo.
\end{abstract}

Essa conceituação, além de abarcar a identidade do sujeito, faz percebermos que cada um, cada identidade, é um fator formador do grupo social no qual o indivíduo está inserido. Podemos, assim, compreender que essa busca de identidade e de sua singularização está diretamente ligada ao fator de construção da identidade e da cultura do grupo. A partir daí, devemos estabelecer uma relação entre identidade e subjetividade, visto que as identidades são formadoras e constroem a cultura de diferentes grupos. Não podemos excluir a interação desses grupos, ou seja, a troca de informações e, por que não, de identidades entre eles.

Portanto, tendo por base que a subjetividade é construída a partir das relações com os outros e consigo mesmo (HERNÁNDEZ, 2007, p.72), acredito que a pesquisa pôde contribuir de forma preponderante para a produção da subjetividade do grupo em foco. 0 trabalho visava, além da singularização da identidade de cada um, manter uma relação com o todo, que trata de construir a identidade coletiva a partir da identidade individual, ou seja, a partir das relações com os outros e consigo mesmo.

Segundo Hernández (2007, p. 72)

A noção de subjetividade, pelo contrário, resgata a capacidade de ação dos indivíduos, para adotar um sentido de ser em diálogo com essas posições que Ihes vêm 'de fora'. É, portanto, uma maneira de construir-se a partir da reflexão (a tomada de consciência sobre si mesmo) na interação com os outros. Desse ponto de vista, a subjetividade é instável, mutável, flexível e múltipla, enquanto a identidade vem a ser estável, rígida e unívoca.

A partir do conceito trazido pelo autor, o qual pontua de forma precisa e objetiva a subjetividade, podemos entender que essa construção se dá a partir da troca, da relação com o outro. A subjetividade pode ser entendida como esse entremeio entre eu e o outro, essa relação que se constitui e que, de certa forma, atua com grande força na construção identitária de cada um, se a entendermos como uma construção baseada nas relações com o mundo. 
Para poder entender um pouco melhor esse conceito de subjetividade, enuncio, ainda, dois conceitos apontados por Silva (2000, p.45). Um deles é a contextualização do conceito de dobra de Deleuze, em sua teorização sobre o processo de subjetivação.

Deleuze busca evitar a referência a qualquer noção de interioridade, de subjetividade prévia ou de sujeito estável, evitando, ao mesmo tempo, qualquer dicotomia ou separação entre interior e exterior, entre 'fora' e 'dentro'. Deleuze concebe o processo de subjetivação como uma 'dobra' tal como uma dobra numa folha de papel ou num tecido, ou, ainda, uma invaginação corporal, [...], por meio da qual o 'fora' torna-se 'dentro' sem deixar de ser 'fora' e sem tornar-se simplesmente 'dentro'.

A conceituação de Deleuze a respeito da subjetividade, na qual o autor busca o termo "dobra" para explicá-la, torna-se um mecanismo facilitador do entendimento, pois passamos a compreender que não podemos separar o "dentro" e o "fora" do indivíduo, entre o que está interiormente e o que está exteriormente. Assim, essas relações tornam-se únicas, e acabam por conversarem entre si, de forma que uma complemente a outra, fazendo com que haja o diálogo entre a identidade e a subjetividade, deixando de lado essa separação.

O outro conceito a respeito de subjetividade, que é enunciado por Silva (2000), a define, muitas vezes, como tomando frente a ser um sinônimo do sujeito, porém, em termos gerais, refere-se às prioridades e aos elementos que caracterizam o ser humano como sujeito. Num certo registro, "subjetividade" opõe-se àqueles elementos que, no ser humano, se distinguem do que é caracteristicamente social, carregando as conotações de interioridade e essencialidade.

Ambos os conceitos abarcam o posicionamento definidor de que a identidade pode ser vista como um fator condicionante na construção da subjetividade. A partir do momento em que há relações com o outro, interação, como o que vemos na definição de Hernández para subjetividade, nesta relação há muito de si, do pensamento próprio, da identidade. Essa troca proporciona um repensar identitário, pois a relação com o outro está repleta de diferentes posicionamentos, que podem fazer uma revisão de posturas frente à construção identitária.

Esses discursos e relações nos quais está presente a individualidade de cada um, e que são formadores da subjetividade individual, estão constituídos de diferentes sujeitos, dependendo de cada discurso, conforme afirma Silva (2000), que traz o sujeito como um ser pensado, correspondendo a certos discursos que, muitas vezes, são diversos e contraditórios. Assim, o conceito de "posição-do-sujeito" concebe a subjetividade como construída, contraditória e fragmentada.

Para Belsey (1991 apud SILVA, 2000, p.93) 
A subjetividade - tal como a identidade - é uma matriz de 'posições-desujeito', que podem ser inconsistentes ou até mesmo contraditórias entre si. A subjetividade é, pois, linguística e discursivamente construída e deslocada ao longo da gama de discursos nos quais os indivíduos concretos participam.

A partir dessa citação, podemos perceber a relação que pode ser feita entre a subjetividade e a identidade, notando que uma está imbricada a outra, e ambas são construídas a partir de um indivíduo. Isso significa que a subjetividade e a identidade não existem sozinhas, sem a presença de um ser pensante e, principalmente, atuante dentro da sociedade, a qual também é entendida e constituída a partir desses dois conceitos.

Portanto, para a tentativa de singularizar a identidade e dar outro significado à subjetividade, busco a posição de Stuart Hall (1997 apud HERNÁNDEZ, 2007, p. 22) para dialogar, versando sobre a ideia de que cada usuário dá o seu sentido e seu significado à linguagem, seja ela visual ou não, e este significado é construído usando sistemas de representação, onde tal representação é a produção por meio da linguagem. Estes conceitos vêm ao encontro da abordagem com a visualidade e a busca da identidade, pois cada sujeito da pesquisa percebe de formas diferentes o que vê através das suas experiências e vivências que foram construídas individualmente e assim produzem diferentes narrativas individuais.

Repensar as subjetividades que, segundo Ferreira (2004, p.550), são "construídas na vivência de relações sociais determinadas, produzem os sentidos que o sujeito atribui às experiências vividas", é um dos fatores que delineia esta pesquisa visto que a partir do momento em que são propostas atividades que possam promover este repensar da subjetividade, os colaboradores passam a refletir um pouco mais sobre as suas próprias identidades e subjetividades que, como Deleuze escreve, não se constituem interiormente e sim a partir de "dobras".

Para Rey (1999, apud FERREIRA, 2004, p. 550),

a subjetividade individual é determinada socialmente, porém, não em forma de um determinismo linear externo, do social para dentro, para o subjetivo, mas sim, em um processo de constituição que integra, de forma simultânea, as subjetividades sociais e individuais. O indivíduo é um elemento constituinte da subjetividade social e, simultaneamente, se constitui nela.

Como já citado anteriormente, esta subjetividade e, por conseguinte, a identidade, acabam por tomar este direcionamento social que se constitui fora do individuo promovendo a construção a partir da atuação individual com o outro e com a sociedade que os rodeia.

Essa união ou ainda conformação dos conceitos entre identidade e subjetividade estão muito presentes. Hall (2000, p. 109) escreve que é porque as identidades são 
constituídas dentro e não fora do discurso que nós precisamos compreendê-las como produzidas em locais históricos e institucionais específicos, através de práticas discursivas, estratégias e iniciativas especificas.

A partir daí penso que as linguagens discursivas visuais, e de outras ordens, colaboram como fator específico da constituição do eu. Gergen (1992 apud COELHO, 2010) escreve que as linguagens se constituem mediante os dispositivos sociais do discurso e suas interpretações se fazem entender através do olhar do outro frente ao que é produzido, elaborado individualmente, estabelecendo-se aí mais um processo de singularização da identidade e o resgate da subjetividade através da relação com o outro e sua visão sobre o eu.

Em função desta subjetividade e identidade estarem atreladas ao meio onde os colaboradores estão inseridos, entendo o lugar cultural de cada um e do grupo como elemento condicionante na relação do indivíduo consigo mesmo e com o outro. Esta realidade social se forma a partir das construções identitárias e subjetivas de cada um, tornando-se assim uma cadeia onde os indivíduos carecem de seu meio para entenderem-se e perceberem-se como sujeitos, e o meio precisa das construções identitárias e subjetivas para ser concebido como meio produtor de culturas e relações sociais.

Para que essa relação possa se construir, buscamos diálogos e imagens, a fim de que esse processo de "conversa" entre identidade e subjetividade flua de uma forma mais dinâmica, pois, segundo Hernández (2011), as imagens agem como um espelho do indivíduo.

Essas imagens advindas da cultura visual são tratadas segundo Martins (2007) não apenas pelo valor estético que elas têm, mas principalmente buscando compreender o papel social da imagem na vida cultural. As imagens passam a ser elemento contribuinte para o ciclo que envolve a identidade e o meio social, pois são elementos carregados de conceitos e atuam como articuladoras, dentro do meio social e da construção de identidades, possibilitando que os sujeitos se posicionem mudando o sentido: de meros visualizadores passam a ser críticos e, conseqüentemente, produtores e consumidores da cultura visual na vida cotidiana, havendo, assim, a construção do meio social.

A compreensão de imagens, segundo Coelho (2010), é de certa forma uma interpretação, é a maneira humana que possuímos para conhecer o mundo, a qual está determinada pela imersão no contexto social daqueles que percebem a imagem. Este fator social acaba por condicionar a compreensão da realidade, não podendo deixar de lado ainda que esta compreensão da realidade está diretamente ligada à forma com que o individuo se constitui, levando-se em consideração que cada um se projeta a partir de seus históricos e vivências dentro do grupo social e, por conseguinte, dentro de um meio social condicionante. 
Neste contexto, as relações entre os sujeitos e as imagens configuram o que Hernández $(1998,2000,2007,2011)$ sinaliza em suas diferentes publicações, como o "entre" que se dá no discurso, no qual se configuram as relações que os indivíduos constroem com as imagens.

\section{Definir relações e construções através do "entre"}

Como instrumentos facilitadores no processo de pesquisa, utilizei os dados do portfólio, as imagens fotográficas feitas por mim e pelos colaboradores e os diários de campo reflexivos. Para compreender os aspectos relevantes que permeiam o levantamento dos dados por portfólios trago alguns pontos enunciados por Eça, em uma entrevista a Assis (2010, p. 217), que define o portfólio como um meio de entender processos, ou seja, de poder nos aproximar do método com que são construídas as aulas, o posicionamento dos alunos, suas angústias, suas colaborações frente ao ensino. A entrevistada ainda enuncia o portfólio como um meio que favorece a autonomia dos estudantes, seu inquérito crítico, a reflexão sobre suas dificuldades fazendo os estudantes refletirem diante do que fora discutido no encontro. O portfólio pode também ser um mecanismo de autoconhecimento, pois ali os colaboradores podem se expressar através de confissões, desenhos, colagens, reflexões, diários, sendo respeitado assim seu estilo de aprendizagem e suas motivações.

Ainda como instrumento de produção de dados, entendo a fotografia como um documento valoroso, pois a partir do momento em que podemos usar os registros de expressões, de processos, de produções, dos retratos dos alunos e ainda as fotografias feitas pelos colaboradores, podemos compreender de uma maneira mais clara o estudo e a forma como este se deu nos encontros, pois as imagens podem remeter de forma mais explícita ao que foi experienciado no momento registrado.

Os diários reflexivos trazem ao estudo registros mais criteriosos do que foi construído nos encontros, de como foram entendidas as propostas, as interações dos colaboradores com o pesquisador. Recordar as falas, as ações e as expressões de uma forma reflexiva, e registrá-las na escrita, pode trazer ao estudo uma consistência que acessa a docência experienciada para compreendermos como se deu o processo e de que forma pode contribuir aos propósitos da pesquisa.

Para esta pesquisa foram planejados oito encontros com os pré-adolescentes da Creche, sendo dois a cada semana, uma na segunda-feira e outro na quinta-feira, com duração de 90 minutos cada um. Nestes encontros foram ministradas oficinas de educação em artes visuais, através de abordagens que pudessem problematizar sobre a singularização da identidade de cada colaborador. 
O primeiro encontro teve como temática a pergunta "Quem é o colaborador?", cujo objetivo era conhecer melhor os participantes e aproximar-me deles através de questionamentos sobre o que fazem fora do período escolar, onde estudam, os nomes, idades, qual a relação com os pais, em que trabalham, quantos irmãos têm, as relações com a mídia, há quanto tempo frequentam a creche, o que gostam de fazer. Utilizei uma abordagem referente ao lixo e à arte, pois de antemão sei que a creche vive em um bairro onde a coleta seletiva é uma atividade que gera renda, realizada por muitos moradores, que fazem o aproveitamento e comercialização do lixo. Questionei, então, se eles conheciam algum catador de materiais recicláveis, que relação eles próprios tem com estes materiais, como esse material pode virar outras coisas que não somente lixo, que relação o lixo tem com a arte, onde o lixo está presente no nosso cotidiano. Questionamentos feitos para embasarem a minha inserção dentro do contexto da creche e dos colaboradores que esta pesquisa abarca. Ainda neste primeiro encontro foram distribuídos cadernos que serviram como portfólio de cada colaborador, neste primeiro momento cada um fez uma capa escrevendo sobre si, suas características, vontades, como e há quanto tempo está inserido na creche, entre outras situações.

No segundo encontro, para poder inserir o lixo e a arte como temática utilizei-me do documentário/filme Lixo extraordinário (2009), que mostra um trabalho do artista plástico Vik Muniz, realizado dentro do maior aterro sanitário do mundo, na cidade do Rio de Janeiro, chamado Jardim Gramacho. Este trabalho visou resgatar e valorizar o cotidiano das pessoas que trabalhavam no aterro através de registros fotográficos que foram "redesenhados" com resíduos do próprio aterro e transformaram-se em obras de arte, em objetos que fizeram as pessoas que ali trabalhavam perceberem seu trabalho como catadores de forma valorizada, e assim consequentemente valorizando as características pessoais de cada uma delas. Inserindo o portfólio como objeto de consolidação dos processos, cada aluno escreveu um pouco sobre sua percepção e compreensão a respeito do documentário.

No terceiro encontro continuei com a temática que fala de lixo arte e inserimos a identidade de cada um, resgatamos o que foi produzido no portfólio do encontro anterior, e discutimos onde o lixo está presente no cotidiano, tanto de forma reciclável, quanto de forma a ser reciclado, registrando no portfólio. Utilizei-me do olhar de cada um frente ao cotidiano a fim de que pudessem fotografar onde este lixo está presente dentro do contexto da creche.

No quarto encontro, trouxe impressões das imagens feitas pelos colaboradores para que pudessem, através da coleta de diferentes materiais, representar estes ambientes através de um tipo de bricolagem, uma união de diferentes materiais do cotidiano como elementos formadores de uma produção plástica referente às imagens por eles registradas. Objetivava que cada um pudesse trazer o seu entendimento, o seu olhar 
frente ao que todos veem e que pode ser "desenhado" de uma forma diferente, que não somente com os materiais específicos para desenhos.

Com a temática que busca singularizar a identidade, propus aproximar-me da realidade do grupo, do bairro, e da família de cada colaborador. No quinto encontro fizemos uma visita ao bairro com o objetivo de conhecermos a casa de cada um e os arredores da creche. Cada colaborador desenhou a sua casa no portfólio, com a percepção que tem dela, enquanto isso foram feitos registros fotográficos tanto das casas quanto dos colaboradores.

No sexto encontro, retomando o que foi produzido no encontro anterior, olhamos os registros fotográficos para perceber se os desenhos trazem aspectos da realidade ou se foram estereotipados, assim cada aluno fez uma avaliação da sua produção. Posteriormente escrevemos no portfólio quem são os moradores da casa, como se constitui cada família, ou seja, contar qual a própria história e da família.

Este trabalho buscou o resgate da história de vida de cada um e as relações no ambiente familiar, a identidade constituída dentro de casa. Quando finalizada a proposta foram utilizados apenas jornais para representar a casa, por meio de recortes e colagens, pensando nas suas formas reais, este tipo de desenho com recortes de jornal, que na maioria das vezes não tem cor, permite pensarmos apenas nas formas que a casa tem, sem que possamos colori-la, de forma que se evidenciam determinados lugares, espaços da casa. Este exercício permitiu que os colaboradores pudessem olhar seus lares como um todo, perceber como ele é constituído estruturalmente a fim de que, posteriormente, pudessem reconhecer-se, no que se refere a como se constituem dentro deste ambiente e como podem fazer este lugar diferente com as suas presenças.

No sétimo encontro, retomei todos os processos pelos quais passamos, bem como o trabalho realizado pelo artista Vik Muniz, como dispositivo para a proposta que consiste no resgate dos retratos dos colaboradores, feitos através de registros fotográficos. Cada colaborador recebeu uma foto sua impressa em uma folha A3 com carbono, e outra folha, tamanho A3, branca. Eles passaram à folha branca seus traços e expressões considerados relevantes, posteriormente trabalharam no desenho com materiais reciclados que eles próprios coletaram, como tampas de garrafas, papéis de balas, entre outros, e configuraram a imagem com esses materiais, assim como o trabalho produzido por Vik Muniz, com os catadores do Jardim Gramacho.

No oitavo e último encontro, retomamos as propostas da aula anterior estabelecendo um olhar crítico e identificador das propostas produzidas, problematizando como as características de cada um estão presentes nos retratos, de que forma e o que cada um pode ver de si no retrato, para então escrever no portfólio de forma que a escrita individual anuncie as reflexões referentes à forma que cada um se constitui como indivíduo. 
A prática das oficinas foi orientada pelo "Esquema Projetos de Trabalho" elaborado pelo doutorando Lutiere Dalla Valle, da Universidad de Barcelona/Espanha, a partir do livro "Cultura Visual, Mudança Educativa e Projeto de Trabalho", da autoria de Hernández (2000).

Segundo Dalla Valle (2010, p. 7 e 8 ),

\begin{abstract}
Uma das características das perspectivas contemporâneas da educação das artes visuais adotadas nesta investigação é seu desejo de propor olhares mais críticos, pessoais e que possibilitem a abertura a uma grande variedade de práticas culturais, ações e experiências estéticas e/ou visuais, de reflexão e de construção de conhecimentos a partir daquelas manifestações estéticas que transcendem o tradicional (tradução própria).
\end{abstract}

Os projetos de trabalho foram abordados como uma metodologia condutora, por sua perspectiva facilitadora para a metodologia desta pesquisa, embasando as propostas desenvolvidas.

Esta dimensão metodológica foi adotada pelo fato de propiciar o envolvimento do grupo com o que é proposto, promovendo uma troca constante entre os colaboradores e o propositor, que envolve o empenho de cada um, com a finalidade de o andamento das propostas assentir de forma consistente.

Os processos pedagógicos foram realizados por meio da educação informal em artes visuais, com subsídios referentes à metodologia de projetos de trabalho, em busca da singularização da identidade e da produção da subjetividade. Foram fomentadas conversas que pudessem contribuir para a reflexão e para se repensarem valores subsidiando o objetivo desta pesquisa e as produções plásticas baseados no processo de educação por projetos, que segundo Hernández, (1998, p.60) é

favorecer a criação de estratégias de organização dos conhecimentos escolares em relação ao tratamento da informação, e a relação entre os diferentes conteúdos em torno de problemas ou hipóteses, que facilitem aos alunos a construção de seus conhecimentos, a transformação da informação procedente de diferentes saberes disciplinares em conhecimento próprio.

E assim, promover entre os colaboradores esse interesse pelo conhecimento e, consequentemente, sobre a singularização da identidade de cada um frente ao ambiente no qual está inserido, buscando nas relações consigo mesmo, com o outro e com o meio possibilidades para refletir a subjetividade.

$\mathrm{Na}$ mediação por projetos de trabalho, são considerados os conjuntos de atividades construídos em volta de um tema, onde o objetivo é basicamente resolver um problema, uma necessidade surgida no grupo.

Estes achados da pesquisa foram tratados pelo método da análise temática citado por Gomes (2004, p. 86), onde o conceito central da compreensão dos dados é o tema que 
pode ser graficamente apresentado através de palavras, frases, resumo. Segundo Bardin (1979, apud GOMES 2004, p. 86), a análise por temáticas consiste em descobrir os núcleos de sentido que compõem a comunicação, a qual pode significar alguma coisa para o objetivo analítico escolhido. Assim, elencando as temáticas advindas do problema, a compreensão dos achados da pesquisa se torna, além de mais objetiva, de fácil acesso a quem posteriormente a utilizará como referência.

\section{O "entre" dentro da construção}

Partindo para a reflexão que se estabelece em torno da perspectiva na cultura visual, não diferencio as imagens como sendo da cultura visual ou da arte, pois as entendo como sendo de dimensões complementares, ou seja, as imagens pertencentes à arte são constituintes da cultura visual, como defende Hernández (2011, p. 43), que afirma a opção de que a cultura visual além de falar a partir de outro lugar da arte, também impulsiona a realização de projetos e práticas geradas no processo de indagação.

Nos encontros o que se tornou evidente foi a aproximação dos alunos com os veículos midiáticos carregados de imagens que os condicionam como indivíduos construtores de identidades. Estas imagens pertencentes à Cultura Visual trazem consigo elementos que favorecem o diálogo, pois trabalhamos a partir do que o aluno estabelece como referência ao que está sendo trabalhado, que advém dos estudos por projetos de trabalho utilizados por mim como ponto facilitador de abordagem e convívio.

Quando questionados em que momento o lixo poderia adentrar no campo da arte de imediato os alunos fizeram relações com o cotidiano e com o trabalho desenvolvido com sucata e roupa arte dentro da creche, em outra oficina de arte, bem como a relação que fizeram com a vinheta da novela Passione (2010) da Rede Globo onde tinham rostos e pessoas feitas com lixo ${ }^{3}$. Este perceber e trazer ao grupo as percepções individuais tornou as aulas momentos de construção de conhecimentos e, principalmente, de troca entre os participantes fortalecendo ainda os processos de subjetividade do grupo.

\footnotetext{
${ }^{3}$ As falas dos colaboradores estão apresentadas em itálico.
} 


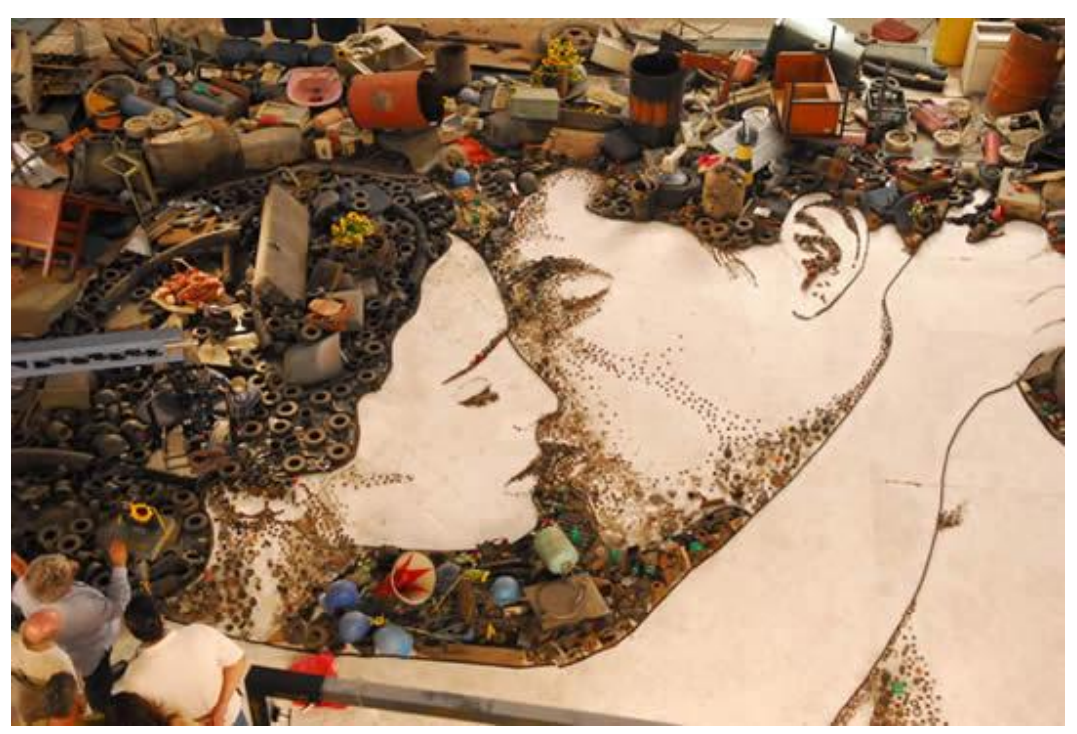

Figura.01 - fonte www.globo.com/passione

Como pondera Hernández (2007, p. 29) um mundo onde o que vemos tem muita influência em nossa capacidade de opinião, é capaz de despertar a subjetividade e de possibilitar inferências de conhecimento mais significativas do que com o que ouvimos ou lemos, desta forma entendo os veículos midiáticos presentes intensamente na cultura visual como formadores da nossa subjetividade, pois se relacionam conosco cotidianamente como personagens presentificados.

Os colaboradores trouxeram ao encontro a relação de proximidade com os materiais reciclados, pois moram em um bairro onde grande parte da comunidade sobrevive da coleta seletiva. Ou seja, estes materiais, esta relação com o que fora construído para a novela, além de ser uma imagem de circulação midiática, tem uma proximidade quando passamos a perceber os materiais que a constroem e que são, para os sujeitos da pesquisa, objetos que carregam tanto uma significação visual quanto identitária.

O filme Lixo Extraordinário (2009), mostrado na oficina, ainda não tinha sido visto por nenhum dos colaboradoes da pesquisa, porém uma das alunas, quando mencionado o nome do artista e do filme, afirmou que ele havia ganhado o Oscar no ano de 2011, ela sabia disso por ter visto em um programa de televisão. A partir desta fala, percebemos que por mais distantes que as pessoas possam estar de museus ou de lugares legitimadores da arte, os meios de comunicação, de certa forma, aproximam as pessoas de imagens advindas do mundo artístico, pois as trazem ao cotidiano, em curtos programas ou em vinhetas de novelas, que se constituem como referências carregadas de significados culturais propostos pela mídia e que acabam propiciando o olhar curioso e a reflexão crítica dos sujeitos. Segundo Dalla Valle (2010, p.8),

os Estudos da Cultura Visual nos favorecem uma amplitude de disciplinas e concepções que nos ajudam a pensar de maneira mais consciente e crítica sobre a intencionalidade destas imagens. Pensar o que estas 
imagens dizem "de mim", "a partir de mim" e como me vejo e me percebo através delas são também, estratégias utilizadas por estas visões da educação atual que nos movem a partir do cinema como um eixo inicial (tradução própria).

As imagens advindas da mídia influenciaram os alunos na construção das capas de seus portfólios. Personagens de desenhos animados e fotos de cantores e atores foram os principais elementos nas produções; estas referências surgem como meios de identificação da personalidade de cada um, na admiração que se mistura com a construção de cada um. O que norteia a perspectiva da cultura visual é poder olhar estas imagens de outro ângulo, com um olhar diferenciado a fim de que se possam construir outras interpretações frente às imagens apresentadas. Porém os alunos as percebem apenas como uma representação de si e não como uma construção de diferentes significados, o que desfavorece este exercício de diferenciar o olhar e construir-se em vez de representar-se.

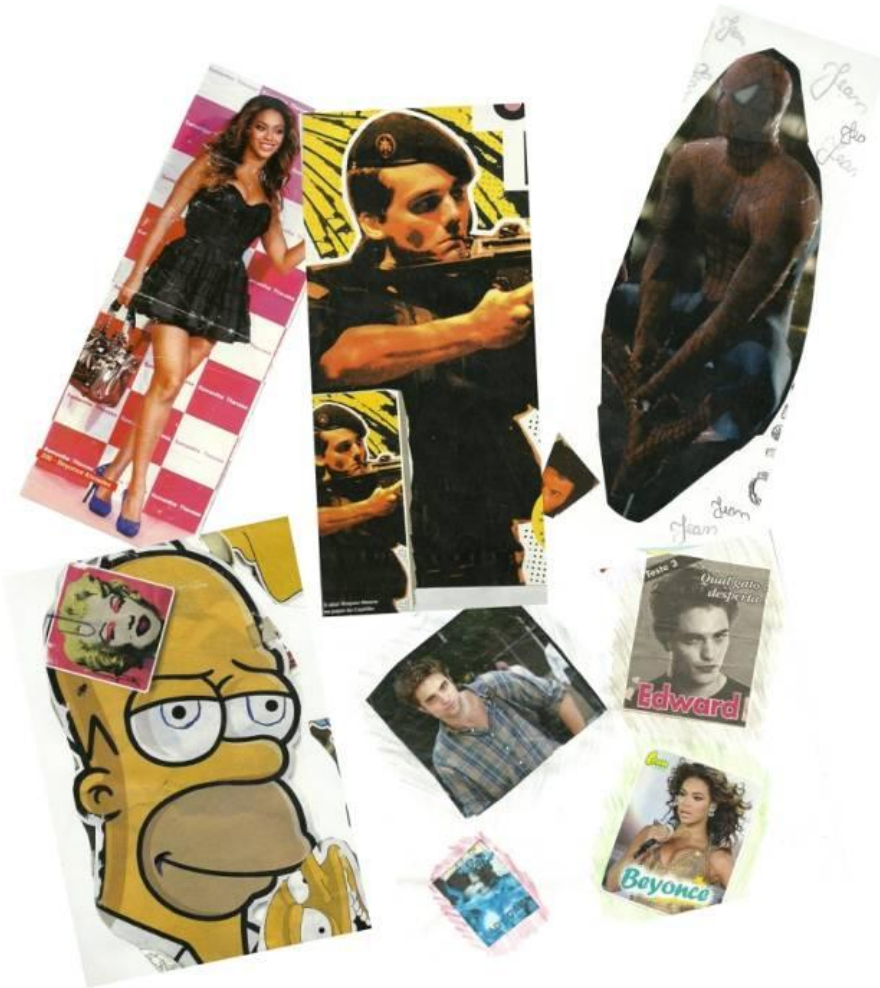

Figura.02 - fonte acervo da autora

Essas referências midiáticas continuaram muito evidentes dentro da proposta de representação das casas através de recortes de jornais, por mais que esses recortes em sua maioria mostrem apenas reportagens e textos. Em algumas páginas apareciam figuras e fotos de personagens e atores da mídia; como se sentiam identificados com tais figuras, queriam de uma forma ou outra utilizar-se delas em seus trabalhos, propondo que pudessem inserir na colagem suas famílias através destes personagens. 
Percebi a presença destes personagens no seu cotidiano principalmente através da televisão, meio de comunicação utilizado diariamente por grande parte das famílias, e que acaba mostrando, além dos personagens, suas características e a personalidade. Isto acaba refletindo na construção da identidade de cada um; também os alunos acabam relacionando esta personalidade aos integrantes da família, nem sempre refletindo as características reais, mas sim as idealizadas pelos próprios alunos que vêem, no que a televisão mostra e apresenta, a vida perfeita e idealizada por todos.

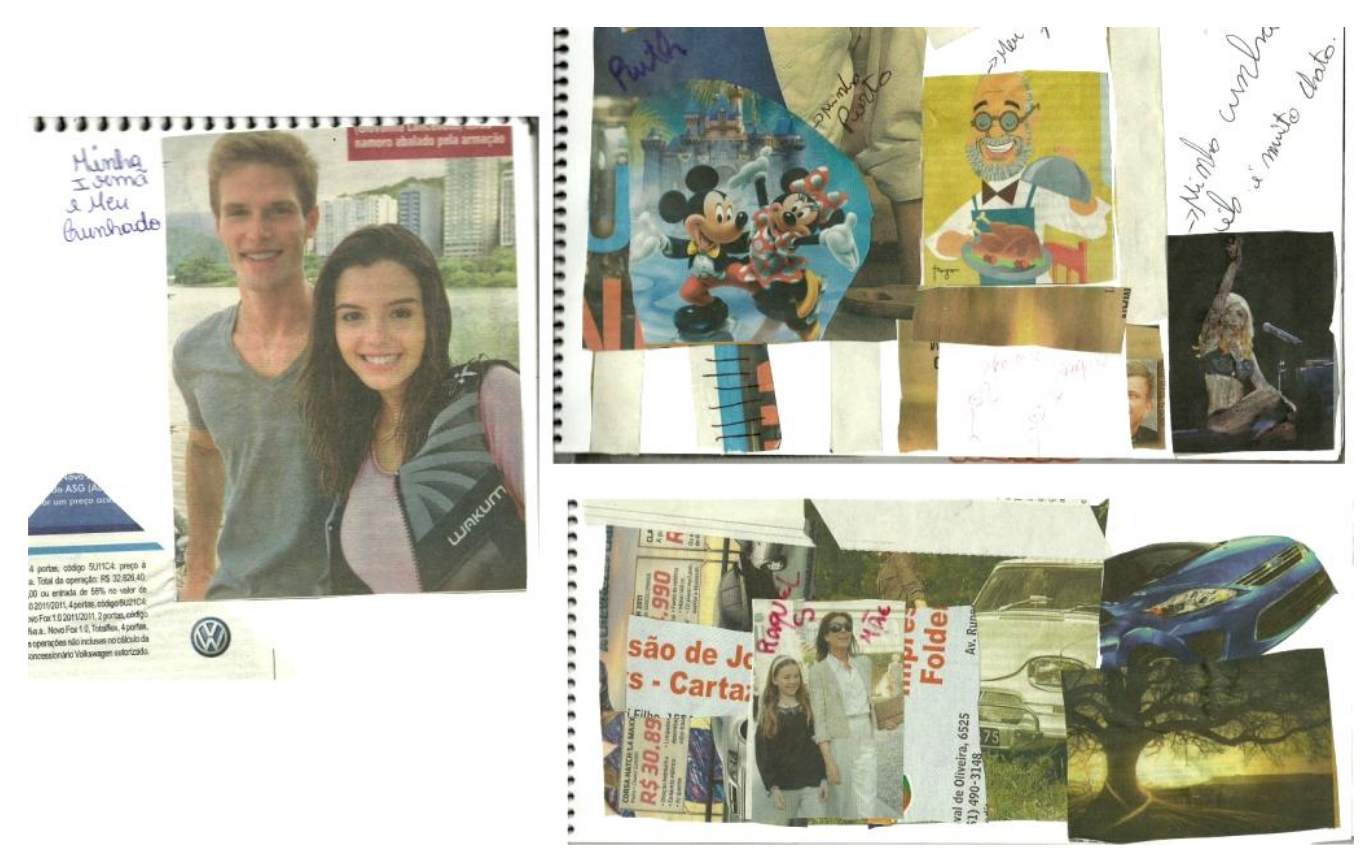

Figura.03 - fonte acervo da autora

Apesar da constante presença da cultura visual no contexto dos alunos, percebo como se torna evidente a relação que se dá entre as imagens e cada um deles. Esta relação entre o eu e as imagens, como cita Hernández (2011, p. 35), propõe uma mudança de foco do olhar e do lugar em que vê. Essa contribuição, além de exercitar o olhar dos colaboradores da pesquisa, trabalha ainda com o olhar do grupo como um todo que passa a perceber de diferentes formas as imagens presentes no cotidiano e, consequentemente, como estas imagens se relacionam com a vida de cada um, podendo propiciar a singularização das identidades.

Quando foram instigados a selecionarem objetos advindos do lixo que pudessem compor os desenhos da última proposta contextualizada com as obras de Vik Muniz, trouxeram aqueles que faziam parte do seu cotidiano, muito semelhantes e comuns, como os papéis de bala. Cada um dizia um pouco de si, assim estes materiais, através da forma como foram organizados no desenho, como foram selecionados, e como foram utilizados antes de serem destinados ao lixo reciclável, contavam muito das relações que faziam com estas imagens e objetos advindos da cultura. 
Entendo que a cultura visual, dentro do trabalho realizado com os colaboradores da pesquisa, em muitos momentos se torna um elemento de construção e muitas vezes de tradução da identidade, o que favoreceu ainda mais os achados desta pesquisa, mostrando onde está presente a cultura de cada um e o lugar onde convivem. Foi possível perceber a relação feita entre as imagens advindas da cultura visual e a percepção de cada um frente a elas. Entendo o momento em que se dá esta relação entre o individuo e a imagem como uma construção individual, em grupo e a consolidação do que entendo por cultura visual, pois assim como Hernández (2011, p. 43), acredito que essa perspectiva

considera a Cultura visual como práticas discursivas - culturais - que tem efeitos nas maneiras de ver e ver-se. (...) O que reafirma a opção de que a cultura visual, além de falar a partir de outro lugar da arte, também impulsiona a realização de projetos e práticas gerados como processo de indagação.

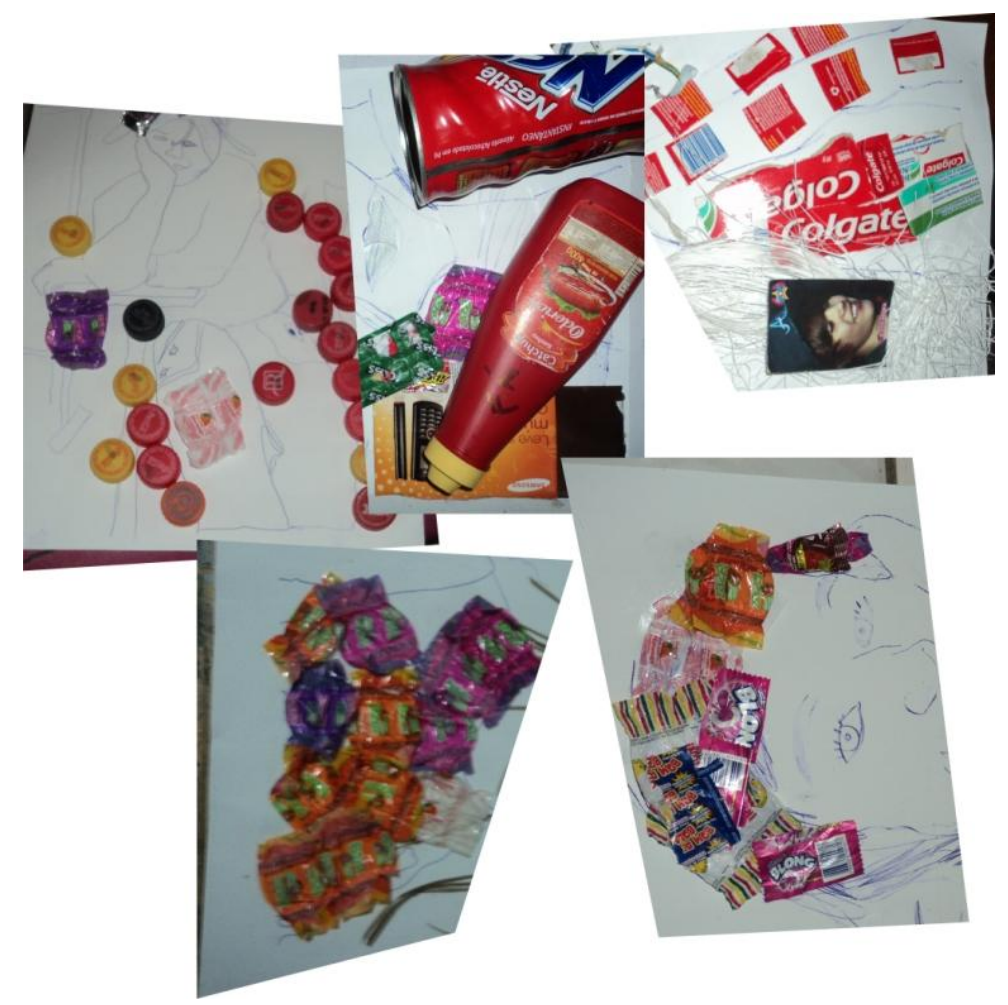

Figura.04 - fonte acervo da autora

Esses processos de indagação são mecanismos formadores e transformadores do indivíduo, e foram trabalhados de forma a direcionar a pesquisa e a temática proposta, a qual aborda os processos de identidade e subjetividade dos sujeitos envolvidos.

Os elementos e as relações advindas da perspectiva da cultura visual foram condicionantes em todos os momentos da pesquisa, tanto nos encontros como nos processos de compreensão dos dados, pois elucidaram a relação dos colaboradores com 
as imagens fazendo com que as identidades fossem instigadas a serem trabalhadas de diferentes formas, fazendo com que os colaboradores da pesquisa pudessem entender de que forma estavam se construindo a partir das imagens e suas relações com o que entendiam como sendo sujeitos de si e do mundo, o que facilitou o processo de singularizarem-se enquanto indivíduos e construírem-se enquanto sujeitos.

\section{Relações e construções do contexto educativo entrelaçado com o processo pedagógico em artes visuais}

Refletindo sobre o processo pedagógico por meio de proposições que puderam facilitar tanto o entendimento dos alunos quanto do professor pesquisador, estabeleceu-se uma permuta em termos de trabalho e de relações construídas entre os participantes, o meio e as imagens.

O projeto de trabalho utilizado como orientador da abordagem metodológica, subsidiando a pesquisa, pode nortear os caminhos tanto para os alunos, que colaboraram de forma muito presente, quanto para o propositor que conseguiu estabelecer e compreender como os processos de negociação e de trocas aconteceram. Esta abordagem veio ao encontro da pesquisa e da metodologia de forma a colaborar com o andamento dos encontros e com os relacionamentos fomentados na oficina.

Hernández, citado no esquema de projetos de trabalho de Dalla Valle (2010, p.01) afirma que os projetos de trabalho têm

\footnotetext{
um enfoque do ensino que tenta ressituar a concepção e as práticas educativas na escola, e não simplesmente adaptar uma proposta do passado, atualizando-a. Quando falamos de projeto, o fazemos pelo fato de imaginarmos que possam ser um meio de ajudar-nos a repensar e refazer a escola. (HERNÁNDEZ apud DALLA VALLE, 2010, p.01).
}

Em alguns momentos, principalmente pela falta de tempo nas oficinas, houve dificuldades nos questionamentos a fim de investigar o uso de certas expressões e imagens, o que pode ter prejudicado o processo de reflexão dos conteúdos dos portfólios. Por mais que os diários contribuíssem no processo de retomada dos encontros, surgiram questionamentos sobre a escolha dos colaboradores e a presença de certas imagens em algumas produções, que poderiam ter sido problematizadas para um entendimento mais complexo de como se deram algumas escolhas.

O processo de relacionamento com os colaboradores da pesquisa se deu de forma intensa e aberta, sendo um agregador significativo no momento de compreensão dos encontros, proporcionando aos participantes envolvidos, repensar ações imbricadas no cotidiano, muitas vezes tão distintas e tão semelhantes, fazendo-nos pensar como as relações podem construir-nos como sujeitos formadores de identidades. Foram relações 
agregadoras no processo educativo, pois entendo esta troca e confiança como sendo um fator que facilitou o envolvimento dos sujeitos da pesquisa.

Para Coelho (2010, p.106),

pensamos como os sujeitos escolares que se formam numa construção discursiva de faz de conta, numa posição idealizadora e idealizada, tem poucos referenciais, nas instituições escolares para se construírem como sujeitos capazes de escrever suas próprias histórias, isto é, para se narrarem como sujeitos.

O que pode ser observado nas instituições de ensino é a ênfase apenas no que possa interessar aos próprios professores e à instituição, muitas vezes, excluindo-se as necessidades, desejos e proposições advindas do aluno, o que pode vir a ocasionar o desinteresse escolar, comprometendo um processo educativo significativo.

Nos encontros da oficina elementos facilitadores do processo pedagógico foram levados aos colaboradores, como imagens, filme, fotografias próprias, que pudessem favorecer a singularização da identidade de cada um, tanto através da fala enquanto propositora quanto no momento de proporcionar os recursos e materiais que pudessem favorecer o entendimento e o relacionamento dos colaboradores consigo mesmos, com o meio e com o grupo.

Quando foram oferecidas revistas de conteúdo diferenciado, que não remetia à mídia cotidiana, de fácil acesso, em um primeiro momento, sentiram-se incomodados, pois as revistas não continham o que procuravam, ou seja, os personagens que faziam parte dos seus cotidianos não estavam ali e não tinha nada de interessante ${ }^{4}$, após manusearem passaram a encontrar personagens e imagens que com as quais pudessem identificar-se, mas mesmo assim os personagens cotidianos continuaram muito presentes nas produções.

Segundo Pereira (2010, p.209),

os sujeitos desenham suas identidades que, de modo dinâmico, se adaptam a uma genealogia de mudanças, em acordo com suas necessidades e interesses e ainda necessidades e interesses da rede social que delineia o espaço cultural de suas comunidades.

Pude perceber, em muitos momentos dos encontros, que os participantes relatavam o que os afligia, muitas vezes relações direcionadas à família e ao convívio da creche. Contavam o que acontecia em casa, em que momentos havia brigas, de quem gostavam e de quem não gostavam na família, como era o relacionamento com seus familiares, amigos, com os colaboradores da creche, enfim, como eram as relações na creche e nas famílias, promovendo o reconhecimento de si e do outro nos espaços de convivência e

\footnotetext{
${ }^{4}$ Fala do colaborador
} 
nas relações constituídas. Sentiram-se de certa forma acolhidos, instigados a trabalharem e procurarem novas visões e versões a partir do que vivenciavam nos encontros.

Seleciono Dalla Valle (2010, p. 02) para entendermos de que forma estes processos de construção partindo dos estudantes tornam relevantes a relação com os projetos de trabalho, onde diz que "deste ponto de vista, a função da aprendizagem está vinculada ao desenvolvimento da compreensão que se constrói como a extensão das possibilidades dos estudantes diante das questões relevantes para a sua vida".

Essa elaboração de relatos, mesmo que fossem sinalizações, promovia construções de suas subjetividades e singularizações de suas identidades no processo de troca com o outro, de relações com o professor propositor e com os colegas, fazendo o exercício do pensar em si, na sua identidade, como cada um se constrói como sujeito de si e do mundo.

Segundo Coelho (2010, p.108), as interações e discursos com que dialogam os participantes, nos processos de construções identitárias, se dá

na busca de se construírem como sujeitos, de compreenderem o outro e o mundo social do qual fazem parte, traçando linhas de fuga, buscando paralelismos não lineares nem geometrizados, tentando não delimitar fronteiras.

Os relatos dos participantes também podem ser compreendidos como momentos em que puderam falar de si. Sem que houvesse "controle" a respeito disso, sentiam-se no tempo e lugar onde foram instigados a construírem-se como sujeitos, fatores estes, que foram significativos no processo de construção e autoconhecimento. Uma possibilidade de

pensar os Projetos de Indagação a partir do que significa, colocar-se no centro da questão, pensar-se a partir do que afeta ao entorno, a partir das dúvidas, a partir do que pode ter diferentes significados e a partir do que se constrói da própria experiência de aprender. (DALLA VALLE, 2010, p. 9)

Os projetos de trabalho, dentro do contexto das oficinas e da forma como foram abordados, puderam dar maleabilidade aos encontros e à pesquisa como um todo. 0 envolvimento dos participantes de uma forma intensa facilitou os processos de construções e de relações dos alunos frente às propostas.

De forma muito clara, Cury e Dalla-Valle (2010, p.14) mostram como se dá o processo pedagógico através dos projetos de trabalho. Neste estudo, direcionado como subsídio facilitador,

o projeto de trabalho é um elemento capaz de originar uma prática pedagógica diferenciada e competente. Por projetos de trabalho 
consideram-se os conjuntos de atividades que trabalham com conhecimentos específicos construídos em volta de um eixo de trabalho, ou tema. O objetivo dos projetos de trabalho é basicamente resolver um problema - uma necessidade surgida no grupo ou um produto final que se deseja. A duração de um projeto de trabalho varia de acordo com seus objetivos e o grau de interesse dos pesquisadores (alunos). É importante lembrar que projetos contêm certa imprevisibilidade, tendo a necessidade de alteração em alguns casos, de acordo com o ritmo e as respostas dos pesquisadores.

Por mais que em alguns momentos tenham sido percebidas dificuldades, como a falta de tempo durante os encontros, a dispersão dos colaboradores com outras atividades, estas vivências foram compreendidas como formas construtoras de experiências, do lugar de onde construo relações, no contexto identitário e subjetivo do espaço da oficina.

Os processos construídos entre os participantes foram possibilidades sinalizadoras para compreender como pode se dar estas relações "entre", envolvendo a si mesmo, ao outro e as imagens, projetando construções e relações que podem vir a favorecer o entendimento de cada um como sujeito de si e do mundo.

\section{Fechamentos abertos de singularizações e subjetivações}

O contexto da cultura visual estabeleceu-se como elemento significativo no processo de construção das subjetividades dos pré-adolescentes, pois estabeleceram-se diálogos com os colegas e relações decorrentes das imagens presentes nos encontros e no cotidiano de cada um. A partilha destas reflexões demonstrou certa maturidade por parte dos colaboradores, pois estes se mostraram abertos à troca e se relacionaram com os colegas de forma muito aberta e dinâmica. Por outro lado, em alguns momentos, envolveram-se superficialmente, pois em determinados encontros os alunos não se interessavam pelo projeto e pelas propostas, saíam da sala, tratavam de outras atividades na creche. Pude perceber que o interesse foi maior quando assistimos ao vídeo/documentário "Lixo extraordinário", estavam atentos, ao que atribuo a proximidade com a realidade dos participantes e o enfoque temático diferenciado.

Por mais que em alguns momentos os alunos não explicitassem de uma forma mais direta suas identidades a fim de que eu pudesse percebê-las nas falas ou nas escritas, mostravam-nas em diferentes comportamentos, relações e construções plásticas que diziam muito de como cada um se constitui como indivíduo. As subjetividades foram instigadas a serem construídas através da troca de informações com os colegas, mesmo que em muitos momentos isso acontecesse naturalmente.

Percebo a identidade e a subjetividade dentro do projeto como elementos de construção mútua, pois ambas andavam lado a lado, tanto na troca entre os colegas, onde cada um dos alunos se posicionava e expunha seus pensamentos mostrando-se assim como 
indivíduos, quanto nos processos de construção coletiva onde prevalecia a construção e identidade do grupo como um todo.

Os projetos de trabalho da maneira como foram abarcados não limitaram a pesquisa e deram o suporte necessário a fim de que os encontros pudessem acontecer de forma dinâmica e com a colaboração dos alunos que se sentiram responsáveis pelo andamento, acontecendo um maior envolvimento de todos que se sentiram valorizados quando indagados a falarem a partir de si, de suas experiências.

Esta forma de entender os projetos de trabalho como mecanismo facilitador e agregador permitiu que os encontros se tornassem prazerosos tanto para os colaboradores quanto para a pesquisadora, pois as negociações permitiram compartilhar conhecimentos e experiências que tornaram os encontros enriquecidos e dinâmicos.

Esta oportunidade de vivência com os colaboradores durante a oficina também colaborou na construção de subjetividades próprias da pesquisadora a respeito das trocas com uma realidade social distante do seu cotidiano. Poder relacionar-se com pessoas com idades e cotidianos tão diferentes, que ao mesmo tempo tem características tão semelhantes, permite perceber que essa troca e construção de subjetividade se deu com importância. Acredito ainda que esta construção afetou diretamente a identidade pessoal de maneira que pude, em muitos momentos, questionar-me como sujeito responsável pelas minhas atitudes sociais diante daquela comunidade em sua carência de conhecimentos e de infraestrutura.

Compreendo que, por mais que em alguns momentos da pesquisa tenham acontecido certas situações que não condiziam com o planejado, pude me utilizar desses fatos para fortalecer a pesquisa. Da mesma forma que os alunos afetaram-se nos momentos reflexivos, de trocas, de construções de saberes, de planejamento dos trabalhos plásticos, puderam ser instigados a singularizarem suas identidades e construírem suas subjetividades através dessas práticas, onde eu também estive aberta aos processos de construções e mudanças.

Acredito, ainda, que esses processos podem continuar a afetar os colaboradores da pesquisa, pois, por mais que as atividades tenham sido encerradas, as vivências e as experiências que fizeram parte de suas histórias pessoais e da história do grupo, como um todo, continuam presentificadas, com a possibilidade de continuar gerando mudanças pessoais, a partir da retomada do processo e da reflexão gerada nos momentos da nossa pesquisa.

\section{REFERÊNCIAS}

ASSIS, Henrique Lima. Sentidos e significados da arte na escola contemporânea: educação artística, ensino de arte ou cultura visual? In: RODRIGUES, Edvânia Braz Teixeira, ASSIS, Henrique Lima. (orgs.). Educação das artes visuais na perspectiva 
da cultura visual: conceituações, problematizações e experiências. Goiânia: SEDUC, 2010. p. $209-234$.

BECKER, Aline da Silveira. Histórias e imagens: a visualidade produzindo infâncias. In: MARTINS, Raimundo. TOURINHO, Irene. (Org.). Cultura Visual e Infância: quando as imagens invadem a escola. Santa Maria: Ed. da UFSM, 2010. p. 89 - 104.

CANCLINI, Nestor Garcia. Diferentes desiguais e desconectados. Rio de Janeiro: Ed. UFRJ, 2009.

COELHO, Roseane Martins. O sujeito e a construção da identidade: implicações na infância, na educação e na arte. In: MARTINS, Raimundo. TOURINHO, Irene. (Org.). Cultura Visual e Infância: quando as imagens invadem a escola. Santa Maria: Ed. da UFSM, 2010. p. $105-129$.

CRECHE ESTAÇÃO DOS VENTOS. Disponível <www.crecheestacaodosventos.blogspot.com>. Acesso em: 23 de maio. 2011.

CUNHA, Suzana Rangel Vieira da. As infâncias nas tramas da cultura visual. In: MARTINS, Raimundo. TOURINHO, Irene. (Org.). Cultura Visual e Infância: quando as imagens invadem a escola. Santa Maria: Ed. da UFSM, 2010. p. 131 - 161.

CURY, Ana Cristina; DALLA-VALLE, Luciana de Luca. Projetos educacionais. Curitiba: Fael editora, 2010.

DALLA VALLE, Lutiere. ¿Qué significa aprender desde Proyectos de Indagación? Revista Digital do LAV - Laboratório de Artes Visuais - Revis LAV Ano III - Número 04- Março 2010. ISSN 1983-7348. Disponível em: <http://www.ufsm.br/lav/>. Acesso em: 2 abr. 2010.

Esquema de Projetos de Trabalho Fernando Hernández. Disponível em: $<$ http://luthiere.wordpress.com/esquema-projetos-de-trabalho-fernandohernandez/>. Acesso em: 13 out. 2010.

FERREIRA, Sueli. A afetividade do aprendente e a prática. Contrapontos, v. 4, n. 3, p. 547-559. Itajaí, set./dez. 2004. Disponível em: <https://www6.univali.br/seer/index.php/rc/article/view/798/650> Acesso em: 15 out. 2010.

GALLO, Silvio. Subjetividade, ideologia e educação. Perspectiva. Florianópolis, v.16, n. 2.9, p.133 -152, jan./jun. 1998.

GIOVANELLA, Alessandra. Invenções cartográficas - uma poética da criação... imagens cotidianas. In: CORRÊA, Ayrton Dutra (Org.). Cartografias contemporâneas da arteeducação. Santa Maria: Editora da UFSM, 2008. p. 83 - 118.

GOMES, Romeu. Análise e interpretação de dados de pesquisa qualitativa. In: MINAYO, Maria Cecília de Souza (org.). Pesquisa social: teoria, método e criatividade. $23^{3}$. ed. Petrópolis: Vozes, 2004. p.79-106.

HALL, Stuart. Quem precisa de identidade? In: SILVA, Tomaz Tadeu da. Identidade e diferença: a perspectiva dos estudos culturais. Petrópolis: Vozes, 2000.

HERNÁNDEZ, Fernando. A cultura visual como um convite a deslocalização do olhar e ao reposicionamento do sujeito. In: MARTINS, Raimundo. TOURINHO, Irene. (Org.). Educação da cultura visual: conceitos e contextos. Santa Maria: Ed. da UFSM, 2011. p. $31-49$. 
- Catadores da Cultura Visual. Proposta para uma nova narrativa educacional. Trad. Ana Death Duarte. Porto Alegre: Editora Mediação, 2007.

. Cultura visual, mudança educativa e projeto de trabalho.

Trad. Jussara Haubert Rodrigues. Porto Alegre: Artes Médicas do Sul, 2000.

; VENTURA, Montserrat. A organização do currículo por projetos de trabalho - O conhecimento é um caleidoscópio. 5a ed. Porto Alegre: Artes Médicas, 1998.

KASTRUP, Virgínia. A Rede: uma figura empírica da ontologia do presente. In: FONSECA, Tânia Mara Galli; KIRST, Patrícia Gomes (Org.). Cartografias e devires: a construção do presente. Porto Alegre: Editora da UFRGS, 2003.

Políticas cognitivas na formação do professor e o problema do devirmestre. In: Educação e sociedade. São Paulo, v. 26, n. 93, p. 1-13. Setembro dezembro/2005.

LIXO EXTRAORDINÁRIO. Direção de Lucy Walker. Rio de Janeiro: Angus Aynsley, Hank Levine, 2009. (99 $\mathrm{min}$ ), son, color.

LIXO EXTRAORDINÁRIO. Disponível em <www.lixoextraordinario.com.br> Acesso em: 16 de março. 2011.

MARTINS, Raimundo. TOURINHO, Irene. Culturas da infância e da imagem "Aconteceu um fato grave, um incidente global". In: MARTINS, Raimundo. TOURINHO, Irene. (Org.). Cultura Visual e Infância: quando as imagens invadem a escola. Santa Maria: Ed. da UFSM, 2010. p. $37-55$.

MARTINS, Raimundo. A cultura visual e a construção social da arte, da imagem e das práticas do ver. In: OLIVEIRA, Marilda Oliveira de. (Org.). Arte, educação e cultura. Santa Maria: Ed. da UFSM, 2007. p. 19 - 40.

MINAYO, Maria Cecília de Souza (org.). Pesquisa social: teoria, método e criatividade. 23a. ed. Petrópolis: Vozes, 2004.

PASSIONE. Disponível em: <www.globo.com/passione> Acesso em: 13 de outubro de 2010.

PEREIRA, Alexandre Adalberto. Estereótipos desenhados, identidades projetadas. In: MARTINS, Raimundo. TOURINHO, Irene. (Org.). Cultura Visual e Infância: quando as imagens invadem a escola. Santa Maria: Ed. da UFSM, 2010. p. $209-226$.

SILVA, Tomaz Tadeu da. Teoria cultural e educação: um vocabulário crítico. Belo Horizonte: Autêntica, 2000.

STAM, Robert. Introdução à teoria do cinema. Campinas: Papirus, 2003.

TRIVIÑOS, Augusto N. Silva. Introdução à pesquisa em ciências sociais: a pesquisa qualitativa em educação. São Paulo: Atlas, 1987. 